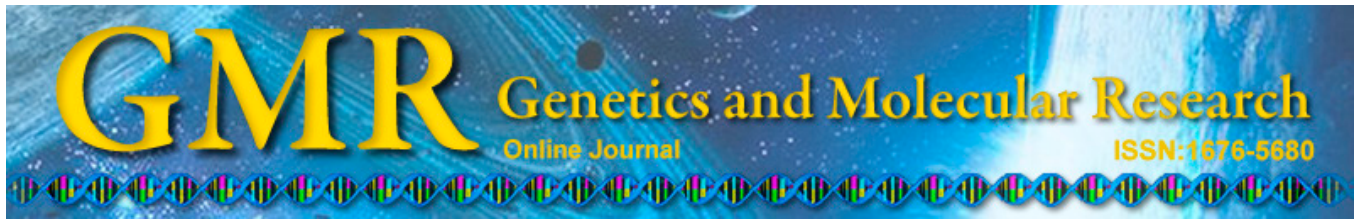

\title{
Selfing confirmation in sugarcane by using simple sequence repeat markers: an individual reciprocal recurrent selection scheme
}

P.M.A. Costa ${ }^{1}$, C.F. Almeida ${ }^{1}$, G. Silveira ${ }^{2}$, B. Soares ${ }^{2}$, D.C.F. Baffa ${ }^{2}$, L.A. Peternelli ${ }^{3}$, L.L. Bhering ${ }^{4}$ and M.H.P. Barbosa ${ }^{2}$

'Laboratório de Biotecnologia e Melhoramento Vegetal, Universidade Federal de Viçosa, Viçosa, MG, Brasil

${ }^{2}$ Departamento de Fitotecnia, Universidade Federal de Viçosa, Viçosa, MG, Brasil

${ }^{3}$ Departamento de Estatística, Universidade Federal de Viçosa, Viçosa, MG, Brasil

${ }^{4}$ Departamento de Genética, Universidade Federal de Viçosa, Viçosa, MG, Brasil

Corresponding author: P.M.A. Costa

E-mail: paulomafra@gmail.com

Genet. Mol. Res. 13 (4): 8962-8970 (2014)

Received October 7, 2013

Accepted March 19, 2014

Published October 31, 2014

DOI http://dx.doi.org/10.4238/2014.October.31.11

ABSTRACT. Superior inbred clones selected in $\mathrm{S}_{1}$ families can integrate an individual reciprocal recurrent selection program in sugarcane by eliminating the genetic load of the population and exploring superior hybrid combinations. Molecular markers can be used for reliable identification of the true selfing-derived clones in these $\mathrm{S}_{1}$ populations. The objective of this study was to confirm true self-fertilized individuals in sugarcane families using microsatellite markers aimed at the use of self-fertilized plants in an individual reciprocal recurrent selection strategy. Self-fertilized individuals 
from five cultivars were genotyped with eight simple sequence repeat (SSR) markers. The markers generated 62 polymorphic markers, with an average of seven polymorphic alleles across the cultivars tested. Three loci revealed highly informative bands and were used to assess the level of selfing in five $\mathrm{S}_{1}$ families. Selfing in these families ranged from 71.7 to $97.6 \%$. The SSR loci provide a reliable and accurate method to identify $\mathrm{S}_{1}$ progenies in sugarcane crosses and can be used as a tool to assist selection strategies in sugarcane breeding programs.

Key words: Saccharum spp; Self-fertilization; Inbreeding; Molecular marker; Genetic breeding; Hybridization

\section{INTRODUCTION}

Sugarcane is cultivated on more than 23 million hectares in tropical and subtropical regions, accounting for almost two-thirds of worldwide sugar production (FAO, 2011). Recently, it has gained increased attention as an important source of renewable biofuel through ethanol production. In addition, new technologies are emerging to convert sugarcane bagasse into second-generation ethanol, which could turn it into an important energy source (Rocha et al., 2011; Siqueira et al., 2013).

Superior cultivars are the base of the sugarcane production chain and should be continuously bred for release to commercial production. The genetic improvement might contribute to $50 \%$ of the productivity gain by means of continuous replacement by other more productive cultivars (Barbosa et al., 2012).

Sugarcane breeders make sexual crosses either between a female and a male (biparental crosses) or among several cultivars (polycrosses), in which the pollen source is not controlled (Heinz and Tew, 1987). Breeders must classify parental clones for use as male or female parents. Flowering clones are determined to be male or female parents on the basis of the level of viable pollen, with female clones having no or low levels of viable pollen. Because emasculation treatment does not guarantee a complete destruction of pollen fertility, some level of selfing seems to be possible (McIntyre and Jackson, 2001).

Selfed sugarcane progeny tend to be inferior to hybrid progeny. The sexual seeds of sugarcane obtained by self-pollination do not germinate very well; the seedlings appear less vigorous, and exhibit lower winter survival frequencies than hybrid seedlings, and the observed performance of the families in the selection is affected (McIntyre and Jackson, 2001; Tew and Pan, 2010; Silva and Gonçalves, 2011). Concerning yield components, Hogarth (1980) and Ferreira et al. (2005) observed that brix is the trait that is least affected by inbreeding depression. In contrast, stalk diameter, stalk height, stalk weight, and stalk number tend to be affected, even though the degree of depression differs between crosses (Silva and Gonçalves, 2011).

Self-fertilization is a general approach that can be used to develop sugarcane varieties. Additionally, inbred lines could be used to form the base populations for reciprocal recurrent selection programs (Ferreira et al., 2005). Resende and Barbosa (2005) recommended selfing the best families for one generation and subsequently selecting the best progenies. These selfing-derived clones selected could be used to create hybrid vigor in crosses because inbreds 
retain good agronomic characteristics of their progenitor (McIntyre and Jackson, 2001; Silva and Gonçalves, 2011).

Selfing is a powerful method for exposing and eliminating deleterious alleles and fixing desirable alleles in commercial breeding clones. Some authors stated that the selfed progenies could be used to infer the genetic load of their respective parents, which could be one more criterion to predict crosses in sugarcane (Ferreira et al., 2005). The ploidy level could mask some favorable alleles within a variety that can be revealed by selfing. Thus, it would be possible to segregate different traits in a particular variety without vigor loss, deriving well-performing inbred clones for traits such as sugar yield and disease resistance (Ethirajan et al., 1978; Cassalett et al., 1996). Silva and Gonçalves (2011) showed that some traits were improved in progenies that originated from selfing and it was possible to identify lines with promising performance for some traits, opening the possibility of accelerated varietal improvement.

In this context, molecular marker technologies allow the accurate determination of the extent of selfing and the identification of true self-fertilization in the progeny. Simple sequence repeat (SSR) markers are highly polymorphic, reproducible, and multiallelic markers that can be analyzed using polymerase chain reaction (PCR)-based methods (Weising et al., 2005). These markers are widely accepted in plant DNA fingerprinting analysis and cultivar identification because of their elevated information content and high discriminatory power (Tew and Pan, 2010; Santos et al., 2012).

The objective of this study was to develop an SSR marker system to confirm selffertilized progeny of sugarcane in order to use self-fertilized progeny in an individual reciprocal recurrent selection strategy.

\section{MATERIAL AND METHODS}

\section{Plant material}

Self-pollinations $\left(\mathrm{S}_{1}\right)$ from five cultivars (RB867515, RB928064, RB865230, RB855536, and RB855156) were conducted at the Flowering and Crossing Station of Serra do Ouro, Murici, Alagoas ( $09^{\circ} 13^{\prime} \mathrm{S}, 35^{\circ} 50^{\prime} \mathrm{W}, 515 \mathrm{~m}$ in altitude) (Barbosa et al., 2002). These privileged location and climate conditions allow the natural flowering of sugarcane, which is necessary for hybridization.

Stalks were isolated in the crossing house to obtain only self-pollinated seeds. The seeds obtained were cultivated at Centro de Pesquisa e Melhoramento da Cana-de-Açúcar of Universidade Federal de Viçosa, in Oratórios, MG $\left(20^{\circ} 25^{\prime} \mathrm{S}, 42^{\circ} 48^{\prime} \mathrm{W}, 494 \mathrm{~m}\right.$ in altitude).

One-hundred and sixty-eight seedlings that originated from the selfing were cultivated in seven randomized complete blocks. Plots comprised two rows of $5 \mathrm{~m}$, with 24 seedlings per plot. From each $S_{1}$ population, 55 plants and each progenitor were randomly sampled for genomic DNA extraction, except seedlings derived from RB855156, which included 30 individuals.

\section{DNA extraction}

Genomic DNA was extracted from fresh sugarcane leaf tissue using the cetyltrimethylammonium bromide method described by Aljanabi et al. (1999). The DNA concentrations 
were quantified using a NanoDrop spectrophotometer ND-1000 (Thermo Scientific, Wilmington, DE, USA) using absorbance at wavelengths of $260 / 280 \mathrm{~nm}$. The DNA was diluted to a working concentration of $12 \mathrm{ng} / \mu \mathrm{L}$ in TE buffer [ $10 \mathrm{mM}$ Tris-HCl, $1 \mathrm{mM}$ ethylenediaminetetraacetic acid (EDTA)].

\section{SSR markers and PCR amplification}

Twenty-four microsatellite sequences were selected from previously reported polymorphic primers based on the polymorphic information content value (Maccheroni et al., 2009; Pan, 2006) and were evaluated in eight commercial cultivars: RB867515, RB928064, RB865230, RB855536, RB855156, RB739359, SP80-1816, and RB925345.

For PCR, a final volume of $20 \mu \mathrm{L}$ was used containing $4 \mu \mathrm{L} 12 \mathrm{ng} / \mu \mathrm{L}$ genomic DNA as template, $4 \mu \mathrm{L} 5 \mathrm{X}$ Colorless GoTaq ${ }^{\circledR}$ Flexi Buffer (Promega Corporation, Madison, WI, USA), $2 \mu \mathrm{L} 25 \mathrm{mM} \mathrm{MgCl}_{2}$, (Promega), $0.8 \mu \mathrm{L} 10 \mathrm{mM}$ dNTP mix (Promega), $2 \mu \mathrm{L} 2 \mu \mathrm{M}$ of each primer, $1 \mathrm{U} \mathrm{GoTaq}^{\mathbb{B}}$ Flexi DNA polymerase (Promega), and sterile distilled water. The PCR amplifications were carried out in a thermal cycler (Veriti Fast 96 well, Applied Biosystems, Inc., Foster City, CA, USA) with the following conditions: pre-denaturation at $94^{\circ} \mathrm{C}$ for $5 \mathrm{~min} ; 37$ cycles at $94^{\circ} \mathrm{C}$ for $40 \mathrm{~s}, 40 \mathrm{~s}$ at an appropriate annealing temperature for each primer, and extension at $72^{\circ} \mathrm{C}$ for $40 \mathrm{~s}$; and a final extension at $72^{\circ} \mathrm{C}$ for $2 \mathrm{~min}$.

\section{Gel electrophoresis}

The PCR amplification products were separated on a $6 \%$ polyacrylamide gel (acrylamide/bis-acrylamide 19:1, Bio-Rad, Hercules, CA, USA) using a 125-bp marker (Promega) to determine the molecular weight of the amplified DNA fragments. The samples were electrophoresed in 1X TBE buffer (0.09 M Tris, $0.09 \mathrm{M}$ boric acid, and $2 \mathrm{mM}$ EDTA, $\mathrm{pH}$ 8.0 ) at $80 \mathrm{~W}$ for approximately $2 \mathrm{~h}$ using a Sequi-Gen GT $^{\circledR}$ system (Bio-Rad Laboratories). The gel was stained by the silver nitrate method with some adjustments (Brito et al., 2010).

\section{Data analysis}

SSR markers were considered to be dominant because, in a polyploidy genome such as that of sugarcane, it is difficult to determine the heterozygosity or homozygosity at any particular locus (Oliveira et al., 2009). Therefore, all alleles (bands) detected in the progenies were scored as either present (1) or absent (0). Progenies were classified as true self-fertilized individuals if they only possessed markers attributable to the female parent. Alleles that were not found in the parent were classified as contaminants (Tew and Pan, 2010).

\section{RESULTS}

\section{SSR marker selection}

Eight microsatellite markers presented low non-specific amplification and banding patterns of high quality; these markers were selected for sugarcane genotyping. An example of the pattern of SSR alleles produced by the CV38 marker among the eight parents is shown in Figure 1. 


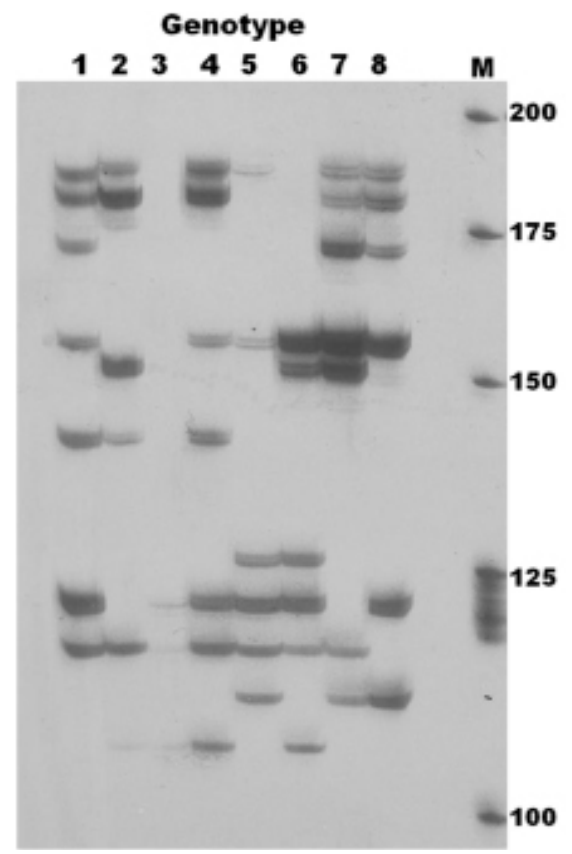

Figure 1. Polyacrylamide gel banding patterns for microsatellite marker CV38 in eight genotypes. Lane $\mathrm{M}=125$ bp molecular weight marker (Promega, USA); lane 1= RB867515; lane 2 = RB928064; lane 3 = RB865230; lane 4 = RB855536; lane 5 = RB855156; lane 6 = RB739359; lane 7 = SP80-1816; lane 8 = RB925345.

The SSR markers SMC24DUQ, SMC31CUQ, SMC336BS, SMC569CS, SMC22DUQ, CV29, CV37, and CV38 produced 7, 7, 6, 6, 6, 13, 12, and 15 alleles, respectively. The eight SSR loci amplified 62 polymorphic alleles in eight genotypes, with the size ranging from 90 to $212 \mathrm{bp}$ and the number of alleles ranging from 6 to 15 per individual. Thus, there was an average of seven polymorphic alleles produced by the markers (Table 1).

Table 1. Microsatellite markers selected for sugarcane: name, SSR repeat, size range, primer sequences, and number of alleles.

\begin{tabular}{|c|c|c|c|c|}
\hline \multirow[t]{2}{*}{ Name } & \multirow[t]{2}{*}{ SSR repeat } & \multirow[t]{2}{*}{ Size range (bp) } & Forward primer sequence $\left(5^{\prime}-3^{\prime}\right)$ & \multirow[t]{2}{*}{ Number of alleles } \\
\hline & & & Reverse primer sequence $\left(5^{\prime}-3^{\prime}\right)$ & \\
\hline SMC24DUQ & $(\mathrm{TG})_{13}$ & $129-150$ & $\begin{array}{l}\text { CGC AAC GAC ATA TAC ACT TCG G } \\
\text { CGA CAT CAC GGA GCA ATC AGT }\end{array}$ & 7 \\
\hline SMC31CUQ & $(\mathrm{TC})_{10}(\mathrm{AC})_{22}$ & $166-210$ & $\begin{array}{l}\text { CAT GCC AAC TTC CAA TAC AGA CT } \\
\text { AGT GCC AAT CCA TCT CAG AGA }\end{array}$ & 7 \\
\hline SMC336BS & $(\mathrm{TG})_{23}(\mathrm{AG})_{19}$ & $173-212$ & $\begin{array}{l}\text { ATT CTA GTG CCA ATC CAT CTC A } \\
\text { CAT GCC AAC TTC CAA ACA GAC }\end{array}$ & 6 \\
\hline SMC569CS & $(\mathrm{TG})_{37}$ & $150-166$ & $\begin{array}{l}\text { GCG ATG GTT CCT ATG CAA CTT } \\
\text { TTC GTG GCT GAG ATT CAC ACT A }\end{array}$ & 6 \\
\hline SMC22DUQ & $(\mathrm{CAG})_{5} \mathrm{C}(\mathrm{AGG})_{5}$ & $160-170$ & $\begin{array}{l}\text { CCA TTC GAC GAA AGC GTC CT } \\
\text { CAA GCG TTG TGC TGC CGA GT }\end{array}$ & 6 \\
\hline CV29 & $(\mathrm{ATCT})_{14}$ & $90-144$ & $\begin{array}{l}\text { TCG CGT CCA CCA ATG TAA CC } \\
\text { GCG TGC ATC GCT TGT GTC TT }\end{array}$ & 13 \\
\hline CV37 & $(\text { TTTC })_{15}$ & $118-170$ & $\begin{array}{l}\text { GGA TGG ACG ACG TGT CCT GG } \\
\text { ATA AAG TGG CCG CTT GGA TTG A }\end{array}$ & 12 \\
\hline CV38 & $(\mathrm{CTTTT})_{18}$ & $108-188$ & $\begin{array}{l}\text { GAA GCA GGG GCC TCA AGT TG } \\
\text { GTC AAA CAG GCG ATC TGG CTC }\end{array}$ & 15 \\
\hline
\end{tabular}




\section{Selfing confirmation}

Among the primers, CV29, CV37, and CV38 showed the highest quality of banding patterns and were selected to evaluate self-progeny in this study. For each marker, 46 putative self-fertilized plants per $\mathrm{S}_{1}$ population (RB867515, RB928064, RB865230, RB855536, and RB855156) were analyzed per gel. The individuals producing non-parental alleles were classified as contaminants (Figure 2). The levels of selfing were 71.7 and $97.6 \%$ in the RB855156 and RB855536 progeny, respectively (Table 2).

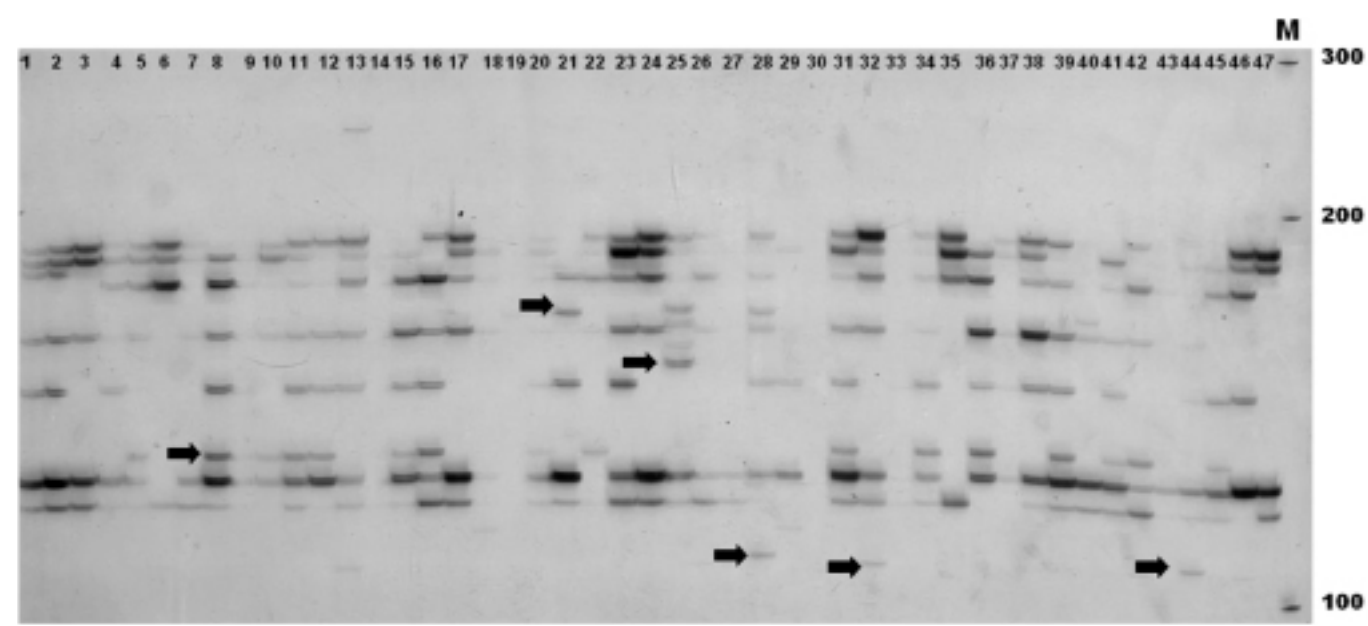

Figure 2. Identification of self-fertilized individuals with a simple sequence repeat (SSR) marker (CV38 locus) in RB867515 progeny. Lane $M=125$-bp molecular weight marker (Promega, USA); lanes 1 and $2=$ RB867515; lanes 3-47, progeny derived from self-fertilization. Arrows indicate examples of non-maternal alleles.

Table 2. Levels of selfing evaluated in five self-fertilized sugarcane clones using SSR markers.

\begin{tabular}{lccc}
\hline Parental & Sex $^{\mathrm{a}}$ & SSR loci & \% Selfing \\
\hline RB867515 & B & CV37 and CV38 & 83.3 \\
RB928064 & F & CV37 and CV38 & 89.3 \\
RB865230 & B & CV29 and CV37 & 91.3 \\
RB855536 & M & CV29 and CV38 & 97.6 \\
RB855156 & F & CV37 and CV38 & 71.7 \\
\hline
\end{tabular}

Sex determined on the basis of level of viable pollen: $\mathrm{B}=$ bisexual; $\mathrm{F}=$ female; $\mathrm{M}=$ male.

\section{DISCUSSION}

The total number of amplicons (62) generated in our study using SSR markers is sufficient to reveal self-pollination in sugarcane crossings. Not all of the 24 microsatellite markers were expected to amplify products from the evaluated clones because most of the SSR markers were derived from the genomic sequences of cultivars that originated from different germplasms (Pan, 2006). In contrast, microsatellites obtained from sequences 
deposited in the expressed sequence tag (EST) database (CV29, CV37, and CV38) had greater potential to generate polymorphism. Maccheroni et al. (2009) demonstrated that the discriminatory capacity of the EST-SSRs CV29, CV37, and CV38 discriminated more than 1200 accessions of the genus Saccharum. As expected, these three loci generated more polymorphic amplicons (average of 13 alleles) than other markers in the eight evaluated cultivars. The number of alleles found in this study was similar to those reported by previous studies using SSR markers in sugarcane (Pan, 2006; Oliveira et al., 2009; Tew and Pan, 2010; Santos et al., 2012; Silva et al., 2012).

The reproducibility and genetic stability of SSR markers have proven this marker system as a useful molecular tool for molecular genotyping, germplasm evaluation, identity testing, and paternity testing of sugarcane progeny (Maccheroni et al., 2009; Pan, 2006, 2010; Tew and Pan, 2010; Santos et al., 2012; Silva et al., 2012). This is the first report of SSR marker-based confirmation analysis in sugarcane progeny derived from self-fertilization. Considering that tassels were isolated to obtain only self-pollinated seeds, the level of contaminants detected in this study can be considered high (Table 2). RB855156 had approximately $28.3 \%$ of its progeny producing non-maternal alleles, while RB855536 had approximately $2.4 \%$ of its progeny producing non-maternal alleles. However, the RB855156 progeny included only a small number of individuals, and high levels of selfing could occur in other crosses.

There was no direct correlation between the sex determined by the level of viable pollen and the percentage of selfing in our study (Table 2). This result is in agreement with that from other studies of sugarcane (McIntyre and Jackson, 2001; Tew and Pan, 2010). Different levels of selfing and outcrossing in sugarcane suggest that crossing procedures must be appropriately delineated to achieve a high degree of genetic purity. The treatment of maternal inflorescence by hot water (Heinz and Tew, 1987) does not guarantee complete emasculation and raises the cost of improvement programs. SSR genotyping enables the accurate and rapid screening of crosses to identify the number of selfed and hybrid progeny.

In polycrosses (Tew and Pan, 2010) and biparental crosses (McIntyre and Jackson, 2001 ), the levels of selfing ranged from 0 to $45 \%$ and 0 to $17.6 \%$, respectively. Our results demonstrated that SSR marker-based fidelity assessment of crosses could be used to delineate appropriate crosses in sugarcane breeding. Resende and Barbosa (2005) proposed implementing the individual reciprocal recurrent selection scheme, which involves one individual from each population and should yield an excellent combination with high total genotypic value and high specific combining ability (Figure 3A). Those individuals that produce superior combinations are selfed to produce two $\mathrm{S}_{1}$ populations, in which the superior individuals are selected to integrate a program of individual reciprocal recurrent selection. Because the primary objective is the use of self-fertilized individuals, reliable confirmation is necessary and should be made by means of SSR analysis (Figure 3B). Therefore, the removal of progenies that contained non-parental alleles is mandatory to develop this scheme. The use of inbred individuals selected from $\mathrm{S}_{1}$ families is intended to explore for one more cycle the superior hybrid combination identified in advance. The mean value of the family $\mathrm{S}_{1 \mathrm{~A}} \mathrm{x} \mathrm{S}_{1 \mathrm{~B}}$ is expected to be higher than the A x B family. Therefore, the probability of selecting new superior individuals will be higher. 


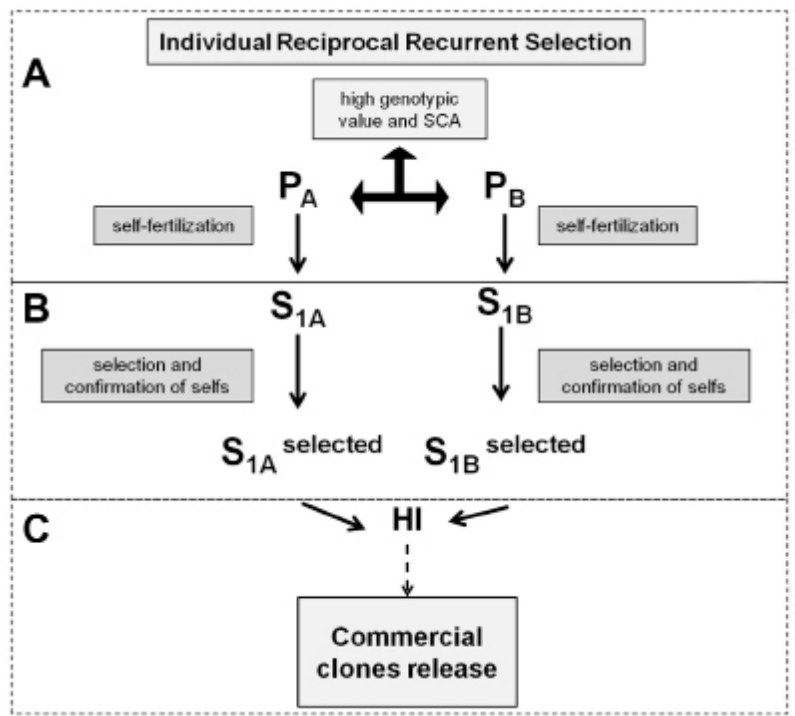

Figure 3. Individual reciprocal recurrent selection scheme in sugarcane breeding. A. Individuals (A and B) from each population $(\mathrm{P})$ with a high genotypic value and specific combining ability are selfed in order to eliminate deleterious alleles. B. From each selfed $\left(\mathrm{S}_{1}\right)$ population, superior individuals are selected, and simple sequence repeat (SSR) analysis is performed to confirm selfing. The selected selfing-derived clones $\left(\mathrm{S}_{1 \mathrm{~A}}\right.$ and $\left.\mathrm{S}_{1 \mathrm{~B}}\right)$ are crossed to create a hybrid combination (HI) and to explore this specific combining ability again. $\mathbf{C}$. Hybrids will integrate the experimental trials aimed at releasing commercial clones.

In conclusion, this study demonstrated that a molecular approach to identify selfed progeny aimed at their use in a reciprocal recurrent selection strategy could be used in sugarcane breeding. In addition, this approach could be applied to the detection of true hybrids for further evaluation and crosses in conventional breeding schemes.

\section{ACKNOWLEDGMENTS}

This study obtained financial support from the Conselho Nacional de Desenvolvimento Científico e Tecnológico (CNPq), Fundação de Amparo à Pesquisa do Estado de Minas Gerais (FAPEMIG), and the Sugarcane Genetic Breeding Program (PMGCA/RIDESA/UFV). David Carlos Ferreira Baffa and Gustavo da Silveira thank CNPq for their student fellowships and Paulo Mafra thanks FAPEMIG and CAPES for his student fellowship.

\section{REFERENCES}

Aljanabi SM, Forget L and Dookun A (1999). An improved and rapid protocol for the isolation of polysaccharide - and polyphenol-free sugarcane DNA. Plant Mol. Biol. Rep. 17: 281

Barbosa GVS, Cruz MM, Soares L, Rocha AMC, et al. (2002). A brief report on sugarcane breeding program in Alagoas, Brazil. Crop Breed. Appl. Biotechnol. 2: 613-616.

Barbosa MHP, Resende MDV, Dias LAS, Barbosa GVS, et al. (2012). Genetic improvement of sugar cane for bioenergy: the Brazilian experience in network research with RIDESA. Crop Breed. Appl. Biotechnol. 12: 87-98.

Brito GG, Caixeta ET, Gallina AP, Zambolim EM, et al. (2010). Inheritance of coffee leaf rust resistance and identification of AFLP markers linked to the resistance gene. Euphytica 173: 255-264.

Cassalett C, Viveros CA and Pizza LF (1996). Self-pollination in sugarcane hybrids, Saccharum sp. Int. Soc. Sugarcane 
Technologists Congr. 1995: 312-315.

Ethirajan AS, Santhakumariamma PN and Velayutham N (1978). Studies on successive inbred generations of selected sugarcane cultivars. International Society of Sugarcane Technologists Congress. Int. Soc. of Sugarcane Technologists Congr. 1977: 269-273.

FAO (2011). FAOSTAT Database. Avaible at [http://faostat3.fao.org/home/index.html]. Accessed March 8, 2013.

Ferreira FM, Barbosa MHP, de Castro RD, Peternelli LA, et al. (2005). Effects of inbreeding on the selection of sugar cane clones. Crop Breed. Appl. Biotechnol. 5: 174-182.

Heinz DJ and Tew TL (1987). Hybridization Procedures. In: Sugarcane Improvement Through Breeding (Heinz DJ, ed.). Elsevier, Amsterdam, 313-342.

Hogarth D (1980). The effect of accidental selfing on the analysis of a diallel cross with sugar cane. Euphytica 29: 737-746.

Maccheroni W, Jordão H, Gaspari R, Moura GL, et al. (2009). Development of a dependable microsatellite-based fingerprinting system for sugarcane. Sugarcane Int. 27: 8-13.

McIntyre CL and Jackson PA (2001). Low level of selfing found in a sample of crosses in Australian sugarcane breeding programs. Euphytica 117: 245-249.

Oliveira KM, Pinto LR, Marconi TG, Mollinari M, et al. (2009). Characterization of new polymorphic functional markers for sugarcane. Genome 52: 191-209.

Pan YB (2006). Highly polymorphic microsatellite DNA markers for sugarcane germplasm evaluation and variety identity testing. Sugar Tech 8: 246-256.

Pan YB (2010). Databasing molecular identities of sugarcane (Saccharum spp.) clones constructed with microsatellite (SSR) DNA markers. Am. J. Plant Sci. 1: 87-94.

Resende MDV and Barbosa MHP (2005). Melhoramento Genético de Plantas de Propagação Assexuada. Embrapa Florestas, Colombo.

Rocha GJM, Martin C, Soares IB, Maior AMS, et al. (2011). Dilute mixed-acid pretreatment of sugarcane bagasse for ethanol production. Biomass Bioenerg. 35: 663-670.

Santos JM, Duarte Filho LSC, Soriano ML, Silva PP, et al. (2012). Genetic diversity of the main progenitors of sugarcane from the RIDESA germplasm bank using SSR markers. Ind. Crop. Prod. 40: 145-150.

Silva DC, Filho LSCD, Santos JM, Barbosa GVS, et al. (2012). DNA fingerprinting based on simple sequence repeat (SSR) markers in sugarcane clones from the breeding program RIDESA. Afr. J. Biotechnol. 11: 4722-4728.

Silva MA and Gonçalves PS (2011). Inbreeding in sugarcane varieties. Ciênc. Rural 41: 580-586.

Siqueira G, Várnai A, Ferraz A and Milagres AMF (2013). Enhancement of cellulose hydrolysis in sugarcane bagasse by the selective removal of lignin with sodium chlorite. Appl. Energy 102: 399-402.

Tew TL and Pan YB (2010). Microsatellite (simple sequence repeat) marker-based paternity analysis of a seven-parent sugarcane polycross. Crop. Sci. 50: 1401-1408.

Weising K, Nybom H, Pfenninger M, Wolff K, et al (2005). DNA Fingerprinting in Plants: Principles, Methods, and Applications. CRC Press, Boca Raton. 